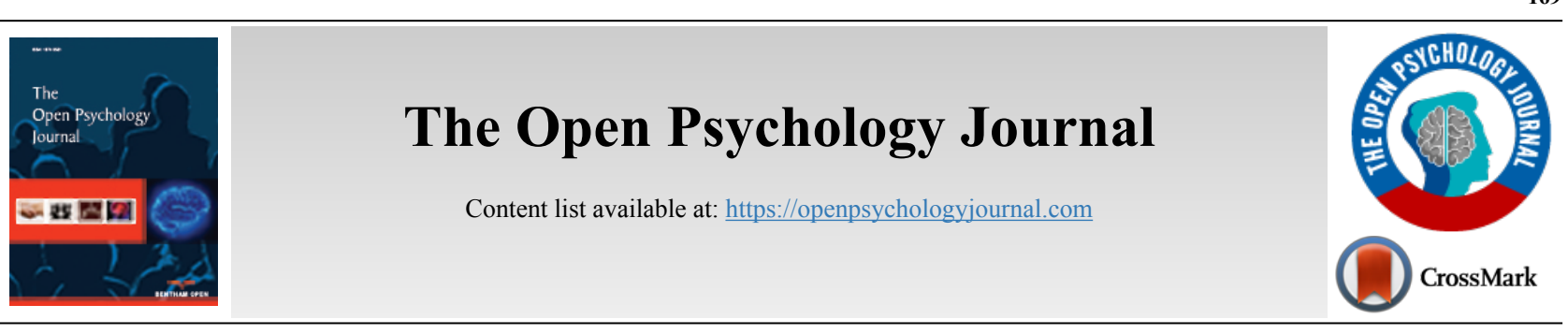

RESEARCH ARTICLE

\title{
Investigating the Physiological Correlates of Daily Well-being: A PERMA Model-Based Study
}

\author{
Xue Feng ${ }^{1,3}$, Xuefei $\mathrm{Lu}^{2}$, Zhuoran $\mathrm{Li}^{3}, \mathrm{Mi}$ Zhang ${ }^{3}$, Jiawei $\mathrm{Li}^{3}$ and Dan Zhang ${ }^{3, *}$ \\ ${ }^{1}$ School of Education, Yangtze University, Jingzhou 434023, P. R. China \\ ${ }^{2}$ Department of Biomedical Engineering, School of Medicine, Tsinghua University, Beijing 100084, P. R. China \\ ${ }^{3}$ Department of Psychology, School of Social Sciences, Tsinghua University, Beijing 100084, P. R. China
}

\begin{abstract}
:
Background:

For decades, psychologists have studied the well-being and its importance in human prosperity.

Objective:

In the present study, a mobile sensing approach was employed to explore the physiological correlates of daily well-being experiences.

Methods:

19 participants were recruited for a 30-day continuous physiological measurement using a smartwatch that collected their heart rates, galvanic skin responses, skin temperatures, and walking steps. They also reported their daily well-being experiences every day, on the five well-being dimensions of the well-established PERMA (Positive emotion, Engagement, Relationship, Meaning, Accomplishment) model. The daily activity data were categorized into four mental states: asleep, relaxed, high mental load, and high physical load.

Results:

344 valid samples of the participants' daily physiological data were obtained from the 19 participants. Using the daily physiological signals of these four states as features, both stepwise regression analyses and binary classification analyses revealed that the five well-being experiences were significantly predicted, with regression r-square values ranging from 0.052 to 0.157 and classification accuracies ranging from $55.8 \%$ to $61.3 \%$.

Conclusion:

The findings provide evidence for the physiological basis of PERMA-based well-being.
\end{abstract}

Keywords: Well-being, PERMA, Daily activities, Heart rate, Galvanic skin response, Skin temperature, Walking step.

\begin{tabular}{|l|l|l|l} 
Article History & Received: January 20, 2020 & Revised: May 10, 2020 & Accepted: May 11, 2020
\end{tabular}

\section{INTRODUCTION}

Well-being is critical for human prosperity. People with greater well-being have a higher life quality than those with lesser well-being [1]. Studies have shown that indicators of well-being, such as positive affect and relationships, are related to greater health outcomes, decreased functional decline, and increased longevity [2 - 8]. While well-being can be evaluated at a national level using wealth-based indexes, such as Gross National Product (GNP), measurement of people's well-being

\footnotetext{
* Address correspondence to this author at the Department of Psychology, School of Social Sciences, Tsinghua University, Beijing 100084, Beijing, China;
}

Tel: 86-10-62773687; E-mail: dzhang@tsinghua.edu.cn at an individual level has gained an increasing interest in recent years, forming a complete picture of well-being [9] (Stevenson $\&$ Wolfers, 2008). Substantial efforts have been devoted over the last two decades to determine the definition and measurement of happiness or well-being [10 - 15]. Compared to the early single-dimensional measurement of mood or life satisfaction, researchers have reached a consensus that wellbeing is a multi-dimensional construct that includes both a good feeling and an effective functioning. There are various definitions and constructs, for example [16 - 20], the wellbeing theory introduced by Seligman represents a fitting summation of the state-of-the-art findings in the field of positive psychology [14]. According to Seligman's well-being 
theory, well-being is an abstract construct that includes both feeling good and functioning well, it is a high level of mental health, and also offered as a guide to help individuals flourish [14]. Seligman describes well-being using the five core dimensions: positive emotion, engagement, relationship, meaning, and accomplishment, which is called the PERMA model. Positive emotion encompasses hedonic feelings, such as happiness, pleasure, and comfort. Engagement represents efforts to be engaged and absorbed in activities that are intrinsically compelling, losing feelings of self-consciousness, and experiencing a sense of time stopping. Relationship underscores high-quality relationships with other people and towards integration with society or a community. Accomplishment is conceptualized as representing accomplishment, success, or mastery of tasks. Meaning is defined as belonging to something larger than the self and feeling connected to something beyond oneself. While the multi-dimensional construct is believed to provide an in-depth overview of well-being and more specific targets (i.e., dimensions) for possible improvements [15, 17, 21, 22], wellbeing is usually measured by self-report based psychological scales, such as the PERMA-Profiler [23].

However, relatively little is known about the physiological correlates of well-being. Positive emotion is probably the only well-being dimension that has received substantial attention from researchers in the field of psychophysiology. Positive emotions, defined as high valence emotional experiences, are associated with changes in cardiovascular indicators, conductance level and temperature of the skin, etc. and their multi-variate combinations. However, the direction of response to elevated positive emotion is not entirely clear. On one hand, many studies suggest that positive emotion involves little or no change in cardiovascular and electrodermal indicators, relative to negative emotions $[24,25]$; on the other hand, some studies show that positive emotion is associated with increased sympathetic nervous system activation, which is reflected in the improvement of cardiovascular activity $[26,27]$. There are still some researches suggesting that positive emotions have the opposite effect, reducing cardiovascular arousal [28].

The research investigating the physiological correlates of other dimensions of the PERMA well-being model is scarce and indirect. With regard to social relationships, it has been proposed that social bindings are characterized by enhanced activation of the vaso-vagal branch of the parasympathetic nervous system [29, 30]. In the field of engagement, accomplishment, and meaning, research on flow experience shows that in the process of completing a challenging task, flow experience is often accompanied by a high degree of physiological activation, such as increased heart rate $[26,30$, 31]. In fact, flow experience often reflects a high degree of engagement, sense of accomplishment, and meaning.

Besides, most of the studies to date have been conducted primarily in laboratory environments, and the emotional experiences were usually elicited either by externally presented auditory/visual stimuli or by imagery. The physiological responses to positive emotions have seldom been systematically addressed in the naturalistic daily life settings [6] (let alone the other four dimensions of well-being). Such an issue could be important, as the rich contextual information in the real world is difficult to be fully reconstructed in laboratory environments [32 - 34]. As well-being is a concept that is closely related to our daily life, it is believed to be better expressed in a naturalistic environment rather than laboratories. Therefore, investigating the physiological correlates of people's well-being experience in daily life settings is expected to promote understanding of the underlying mechanisms of well-being.

The rapid development of mobile sensing technology could provide an important approach for the investigation of wellbeing in daily life settings [35 - 37]. By using mobile phones and wearable sensors, mobile sensing technology enables researchers to sense a variety of people's daily life activities, such as their physical activities, mobile phone behaviors, physiological responses, etc. Using custom-developed mobile applications, researchers have investigated subjective experiences, such as happiness, morality in daily life, and their psychological consequences [38 - 43]. People's mobile phone activities, such as their phone calls, SMSs, and application usage patterns, have been utilized to reveal daily stress, happiness, general emotion, and even personality. More importantly, physiological activities collected in daily life settings by wearable sensors have been employed to reflect mental workload, emotion, etc., based primarily on electrodermal and cardiovascular responses [44 - 47]. The number of studies conducted in daily life conditions is still very limited compared to those carried out in laboratory settings. Nevertheless, increasing attention has been attracted to the mobile sensing-based approach [48], as the findings based on daily life data are believed to have better generalizability to real-world situations.

The present study aimed to investigate the physiological correlates of well-being in daily life settings. The participants wore smartwatches that collected their physiological activities continuously for 30 days. They reported their daily well-being at the end of each day through a mobile application, as measured in the five PERMA dimensions. Their contextual information was derived based on their smartwatch recordings and categorized into four states, including asleep, relaxed, high mental load, and high physical load. The physiological activities were divided into these four states and averaged per day as features. Correlation analyses were performed to examine the univariate links between these physiological features and daily well-being reports. Multi-variate regression analyses and classification analyses were conducted to provide an overview of the predictability of well-being based on these physiological activities. As most of the relevant research has focused on positive emotion and the explorations in naturalistic settings are very limited, the present study is quite exploratory. Nevertheless, it is expected that well-being could be well characterized by daily physiological activities, given the large number of studies demonstrating the close relationship between a variety of cognitive states and physiology $[33,49,50]$.

\section{METHOD}

\subsection{Participants}

Nineteen students (11 female) from Tsinghua University 
(between 19 and 29 years old, mean age 22 years) participated in the study. The sample size was decided following previous studies using mobile sensing techniques, e.g [51, 52]. All the participants were recruited from an undergraduate research project at the Tsinghua University, and were healthy, nonsmokers, normotensive, not on any medication, and had no history of cardiac disease by self-report. They gave their informed consent. The study was conducted following the Declaration of Helsinki and approved by the Tsinghua University Research Ethics Committee in the Psychology Department.

\subsection{Procedure}

Participants completed an online questionnaire on their demographic and background information. Then they received a training on how to use the smartwatch. The daily surveys began approximately 3 days after the initial survey.

The participants were instructed to wear the smartwatches (Basis B1, Intel, USA) for 30 consecutive days throughout the day and night, with only exceptions, such as taking showers, swimming, smartwatch charging (approximately 2 hours every 4-5 days), etc. Their daily well-being reports were collected at the end of each day, right before going to bed, using their mobile phones.

\subsection{Measurements}

The daily physiological and behavioral data were collected using the Basis B1 smartwatch, which is a wrist-worn device capable of recording heart rate (beats per minute), galvanic skin response $(\mu \mathrm{S})$, skin temperature (Fahrenheit), and walking steps (steps per minute). The effectiveness and accuracy of the physiological measurement of the Basis smartwatch have been proved in previous studies $[53,54]$.

The recorded data were uploaded to the cloud server of Basis company through the mobile phone application (Basis, available for both iOS and Android) installed on the participants' mobile phones. The participants were required to upload their data as frequently as possible. The uploaded data were then downloaded in CSV format by the experimenters using customized PHP codes. The downloaded data consisted of values of heart rate, galvanic skin response, skin temperature, and walking steps for every minute during the recording period. The minutes with invalid recordings (due to extensive motion, loose wearing, etc.) were automatically recognized and marked by the official Basis algorithm.

The daily well-being was measured by using a mobile phone-based questionnaire, implemented by the WeChat messenger (Tencent, China) together with the Sojump online survey platform (Sojump, China). The participants were instructed to send a specific message to the experiment account on WeChat when they were ready to report their daily wellbeing statuses, right before going to sleep every evening. The WeChat experiment account then automatically prompted them with a link to the corresponding daily well-being questionnaire. The participants were required to retrospect their daytime wellbeing experiences and then rated their well-being status in the five PERMA dimensions, each with a 6-point Likert scale. To ensure a good understanding of the PERMA dimensions and, therefore, an accurate rating, each level was supplemented with a short descriptive statement. Additionally, two questions were asked before the PERMA scale about the general daily life satisfaction, and an open question was added at the end of the questionnaire about important daily events. In the present study, the focus was on the five PERMA questions. The questionnaire was presented in Chinese (The questionnaire and its English translation are provided in the Appendix). The experimental procedure is shown in Fig. (1).

\subsection{Data Pre-processing: State Definition}

The most challenging issue for the analysis of the physiological data in daily settings is the lack of well-defined contextual information as usually and easily available for laboratory-based studies. Without contextual information, the interpretation of these physiological data could be complicated. For instance, heart rate increases could be an effective indicator of psychological stress, but metabolic demand caused by physical activity can also bring such increases.

To resolve such ambiguity, we make use of the multidimensional physiological and behavioral data (heart rate, galvanic skin response, skin temperature, and walking steps) from Basis B1 to have a refined definition of the daily mental states. Following the previous studies facing a similar dilemma [55 - 57], the daily recordings of heart rate and walking steps were taken for the definition of the four prominent states: high physical load, high mental load, relaxed, and asleep. Specifically, the high physical load state referred to the mental state with both high physical activities (reflected by walking steps) and high activation of the nervous system (mainly reflected by heart rates); the high mental load state referred to the state with high heart rates but low physical activities; the relaxed state referred to the state with low heart rates and low physical activities; the asleep state was associated with extremely low heart rates and physical activities. Note that the data from the asleep state was taken from the night preceding the day for well-being reports because nearly all the participants reported that they usually went to sleep after 00:00 at night. Galvanic skin response and skin temperature were not used for these definitions because of the lack of literature about these two signals. The categorization into these four states is expected to provide more contextual information about the participants and support a more effective usage of these daily recordings. 


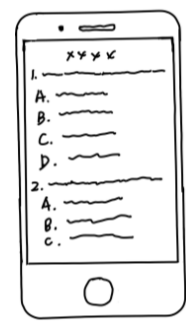

Morning

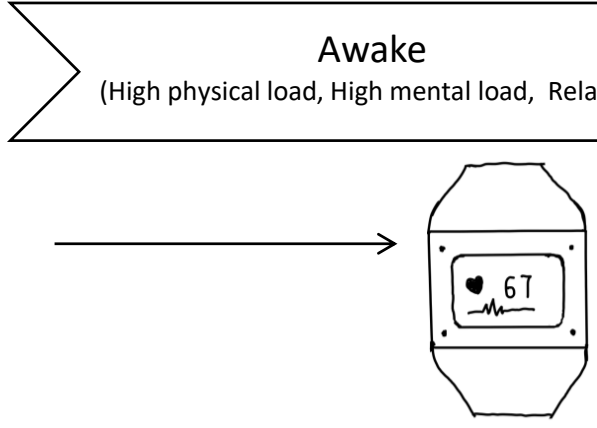

Evening
Daily well-being measured by

Smartphone

Fig. (1). The experimental procedure.

The categorization of the four mental states was achieved by using a k-means clustering method. Using heart rates and walking steps per minute across the 30 recording days per participant, the k-means method automatically formed four clusters (the number of clusters was set to four) and assigned each minute to one of the four clusters. The four clusters of all participants fitted very well with the expected characteristics of the four defined mental states (see Results). Also, five minutes immediately after a high physical load state were manually recategorized as high physical load as well, to avoid a possible miscategorization into the high mental load state (although the corresponding walking steps could be low and the heart rates could remain high). Only the one-minute data with valid recordings were used in the k-means analysis. The k-means method was applied for each participant separately, to allow an adaptive categorization with the individual differences taken into consideration.

The mean and standard deviation of the recorded physiological data (heart rate, galvanic skin response, and skin temperature) were then calculated for the minutes assigned with the same mental state, within every single day for each participant, respectively. Besides, the mean of the walking steps was calculated for the high physical load state. These data were then normalized across the days within each participant, as follows:

$$
Z_{i k}=\frac{X_{i k}-\mu_{k}}{s_{k}}
$$

Where, $Z_{\mathrm{ik}}$ represents the normalized value of one physiological or behavioral index $\left(\mathrm{X}_{\mathrm{ik}}\right)$ on the $i$-th day of the $k$ th participant. $\mu_{k}$ and $s_{k}$ denote the mean and standard deviation of the to-be-normalized value across all days of the $k$-th participant. The normalization procedure is expected to account for the inter-individual differences: A larger absolute value of
$\mathrm{Z}_{\mathrm{ik}}$ indicates a relatively larger deviation from the average daily status. The above-described procedure yields 3 (data type: heart rate, galvanic skin response, and skin temperature) $\times 2$ (mean and standard deviation) $\times 4$ (mental states: high physical load, high mental load, relaxed, asleep) + walking steps in high physical load $=25$ physiological and behavioral parameters per day.

Although the recorded data have a nested data structure that seems to be suitable for a multi-level analysis, the abovementioned normalization procedure was preferred as it is expected to yield a more stable result given the relatively small sample size. By adopting the normalization procedure, a total number of 344 valid samples (see Results) were obtained across the participants and days, which is a reasonable number for regression analysis with 25 variables (i.e., the physiological and behavioral parameters).

\subsection{Data Analysis}

A Pearson correlation analysis was first performed to evaluate the pairwise relationship between the physiological and behavioral data ( 25 parameters) collected by the Basis smartwatch and the well-being report (5 items) from the mobile phone questionnaire. Next, five multiple stepwise regression analyses were conducted to identify the influencing parameters out of the 25 daily physiological and behavioral parameters on the five daily well-being indexes, respectively. Finally, a series of binary classification analysis was carried out to assess the predictive powers of the physiological and behavioral recordings on these daily well-being indexes. The binary classifications were performed for each well-being index separately to achieve an approximately balanced number of samples for the two classes, the days with scores of 1-4 and 5-6 were labeled as two separate classes for positive emotion and engagement, whereas the days with scores of 1-3 and 4-6 were labeled as two separate classes for engagement, accomplishment, and meaning. The percentages of samples for 
the classes with lower scores ranged from $36.9 \%$ to $58.4 \%$. All of the 25 parameters were used as features for classification. All the reported results were based on the leave-one-out crossvalidation procedure.

Data pre-processing was conducted in Matlab (R2015b, MathWorks, USA), and the Statistical Package for Social Sciences (SPSS 20.0, IBM, USA) was used for the statistical analyses.

\section{RESULTS}

\subsection{Descriptive Statistics}

All of the 19 participants completed the whole experiment process and contributed valid data. For the physiological data, the days with recordings of less than 3-hour total asleep time or less than 3-hour total awake time were excluded from data analysis, to provide sufficient data for a reliable daily estimation of the recordings in the four mental states. For the self-reported data, a total of 495 valid daily well-being reports were returned, with a response rate of $86.8 \%$. The physiological and self-reported data was then matched by dates. It was found that the recordings of a total number of 344 valid days from 19 participants were included in this study, ranging from 9 to 32 days per participant $(18.1 \pm 6.8$ days on average). For the included days, $1079.9 \pm 171.0$ minutes of valid recordings were obtained per day. A description statistic of the five dimensions of daily well-being survey among 344 days are shown in Table 1. For the 6-point scale (1-6), the rating of the relationship showed the highest average score (4.3 $\pm 1.0)$ and meaning the lowest $(3.7 \pm 1.1)$. There is the highest correlation between positive emotion and relationship (0.815) and the lowest correlation between engagement and relationship (0.414).

\subsection{Categorization of the Four Mental States}

The circadian rhythm averaged over all participants of the recorded physiological signals and physical activities (steps per minute) is illustrated in Fig. (2). A lower level of heart rate (HR) and physical activity (walking steps, WS) was observed when the participants were probably asleep (approx. $0 \mathrm{AM} \sim 9$ AM); Skin Temperature (ST) showed an opposite trend, with lower values during the day time; galvanic skin response (GSR) depicted a complicated pattern that could not be easily explained by day and night. Nevertheless, the multi-variate data was expected to provide a better description of the participants' status, serving as the basis for the categorization.

The centers of the four clusters by the k-means method of each participant are summarized in Fig. (3a). Although interindividual differences were observed, the centers fitted well with the expected characteristics of the defined four mental states. The cluster analysis result for one representative participant (No.14) is shown in Fig. (3b). Reasonable activity patterns were seen for all days: the asleep state was generally categorized for the minutes between $0 \mathrm{AM}$ and $9 \mathrm{AM}$, which was indeed the usual sleeping time period for the recruited students. Besides, the clustering results on the asleep state fitted very well with the automatically recognized asleep state by the Basis smartwatch. The average valid recording time durations are $425.47 \pm 136.95$ minutes per day for the relaxed state, $80.13 \pm 56.53$ minutes per day for the high physical load state, $417.64 \pm 119.03$ minutes per day for the asleep state, and $156.70 \pm 92.56$ minutes per day for the high mental load state.

\subsection{Correlation and Regression Analysis}

The pairwise correlations between the physiological and behavioral parameters and the well-being indexes are shown in Table 2. The daily experience of Engagement was positively correlated with the HR during high mental load state $(r=$ $0.178, p<0.01)$, and the standard deviation of the GSR $(r=$ $0.134, p<0.05)$ and the ST $(r=0.136, p<0.05)$ during high physical load state. The daily experience of Relationship was negatively correlated with the $\operatorname{HR}(r=-0.167, p<0.05)$ and its standard deviation $(r=-0.182, p<0.05)$ during asleep state, as well as the HR standard deviation $(r=-0.182, p<0.05)$ during relaxed state. The daily experience of Meaning revealed both negative correlations with the $\operatorname{HR}(r=-0.185, p<0.05)$ and its standard deviation $(r=-0.201, p<0.05)$ during asleep state, and positive correlations with the HR $(r=0.295, p<0.01)$ and the GSR $(r=0.120, p<0.05)$ during high mental load state and the GSR $(r=0.140, p<0.01)$ and its standard deviation $(r$ $=0.135, p<0.05)$ during high physical load state. The daily experience of Accomplishment showed a similar pattern as Engagement, with an additional positive correlation with the GSR $(r=0.116, p<0.05)$ during high mental load state.

The stepwise regression results are summarized in Table 3. There was a significant association between the physiological and behavioral parameters and all the five well-being indexes. The primary contributors are the HRs in different mental states, with the contributions of ST, GSR, and WS for some of the well-being indexes. Stepwise regression analyses using the unclustered parameters (i.e., the mean values of HR, ST, GSR, and Step across a whole day, without performing the clustering analysis) were also conducted. However, none of these regression models revealed significant results (all $p>.05$ ).

\subsection{Classification Accuracies}

The binary classification accuracies are shown in Fig. (4). Using the clustered parameters as features, the classification accuracies achieved $55.8 \%, 56.7 \%, 61.3 \%, 59.9 \%$, and $56.7 \%$ for the well-being experiences of Positive emotion, Engagement, Relationship, Meaning, and Accomplishment. By contrast, the classification results based on the unclustered parameters as features revealed only chance-level performances, i.e., $51.7 \%, 51.2 \%, 43.4 \%, 50 \%$, and $48.8 \%$ for the five well-being experiences (in the order of PERMA). 

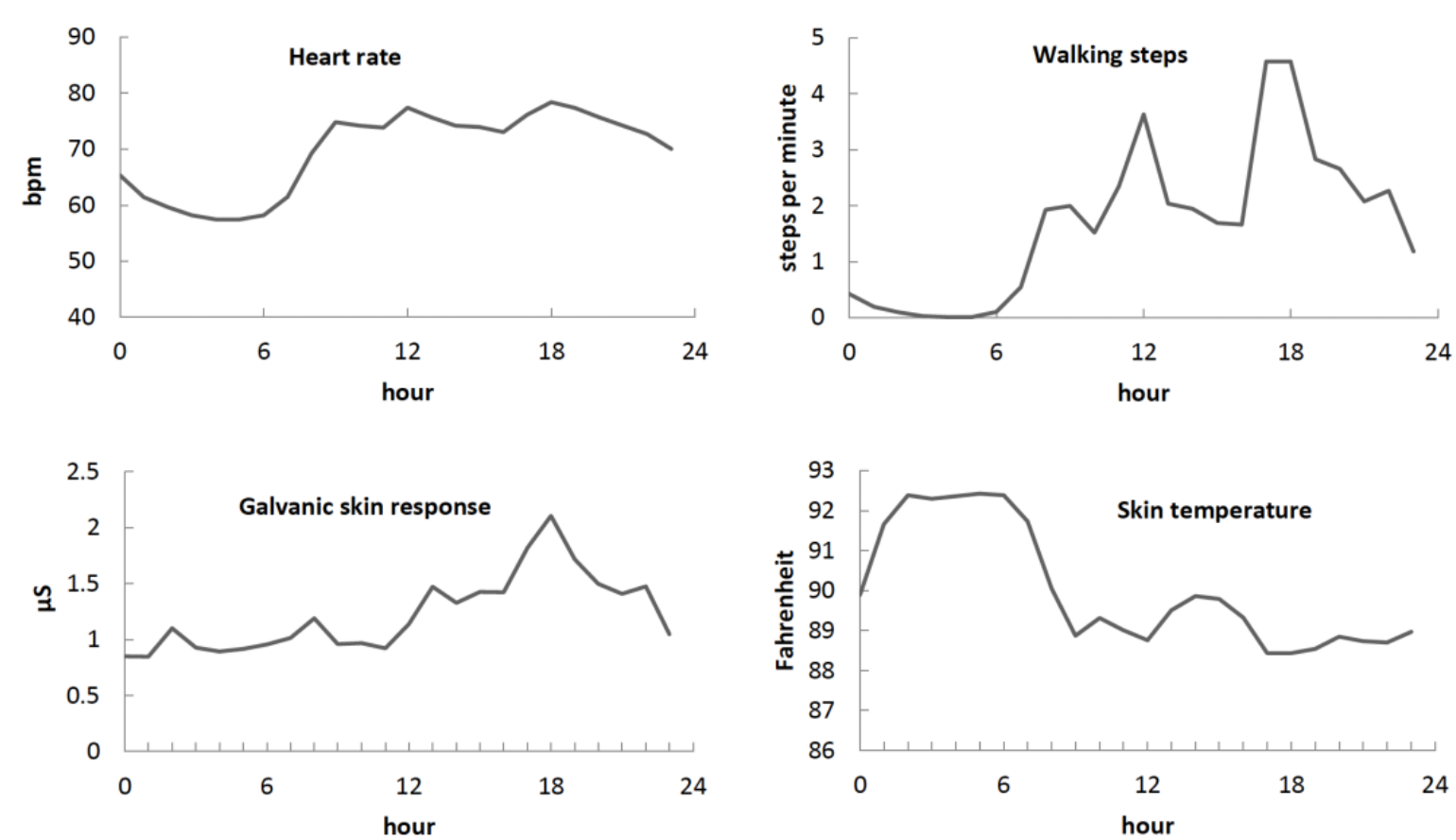

Fig. (2). The circadian rhythm of Heart Rate (HR), Galvanic Skin Response (GSR), Skin Temperature (ST), and Walking Steps (WS), averaged over all participants.

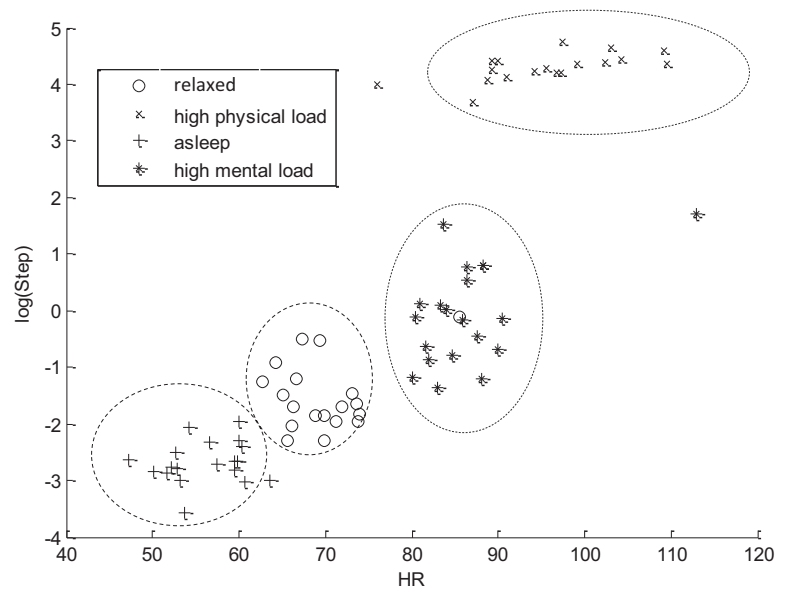

(a)

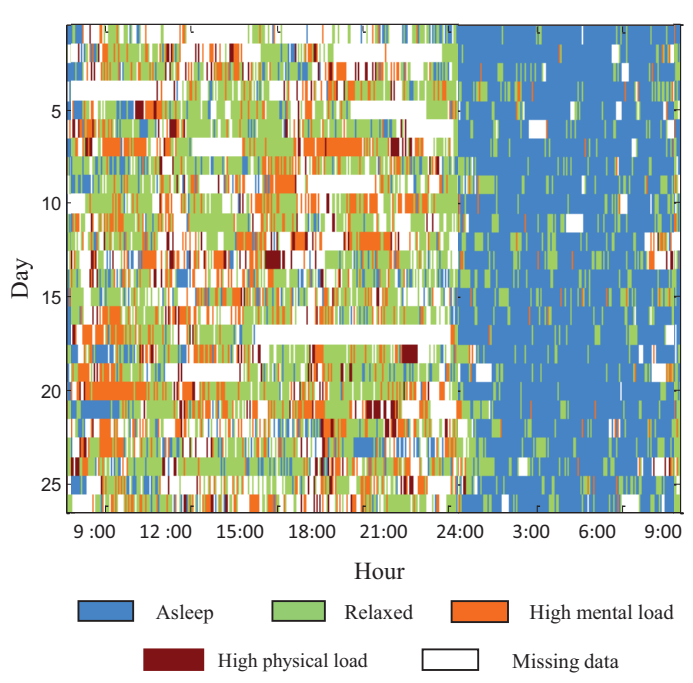

(b)

Fig. (3). (a) Cluster centers for all participants. (b) Clustering daily timescale of a representative participant's data. 


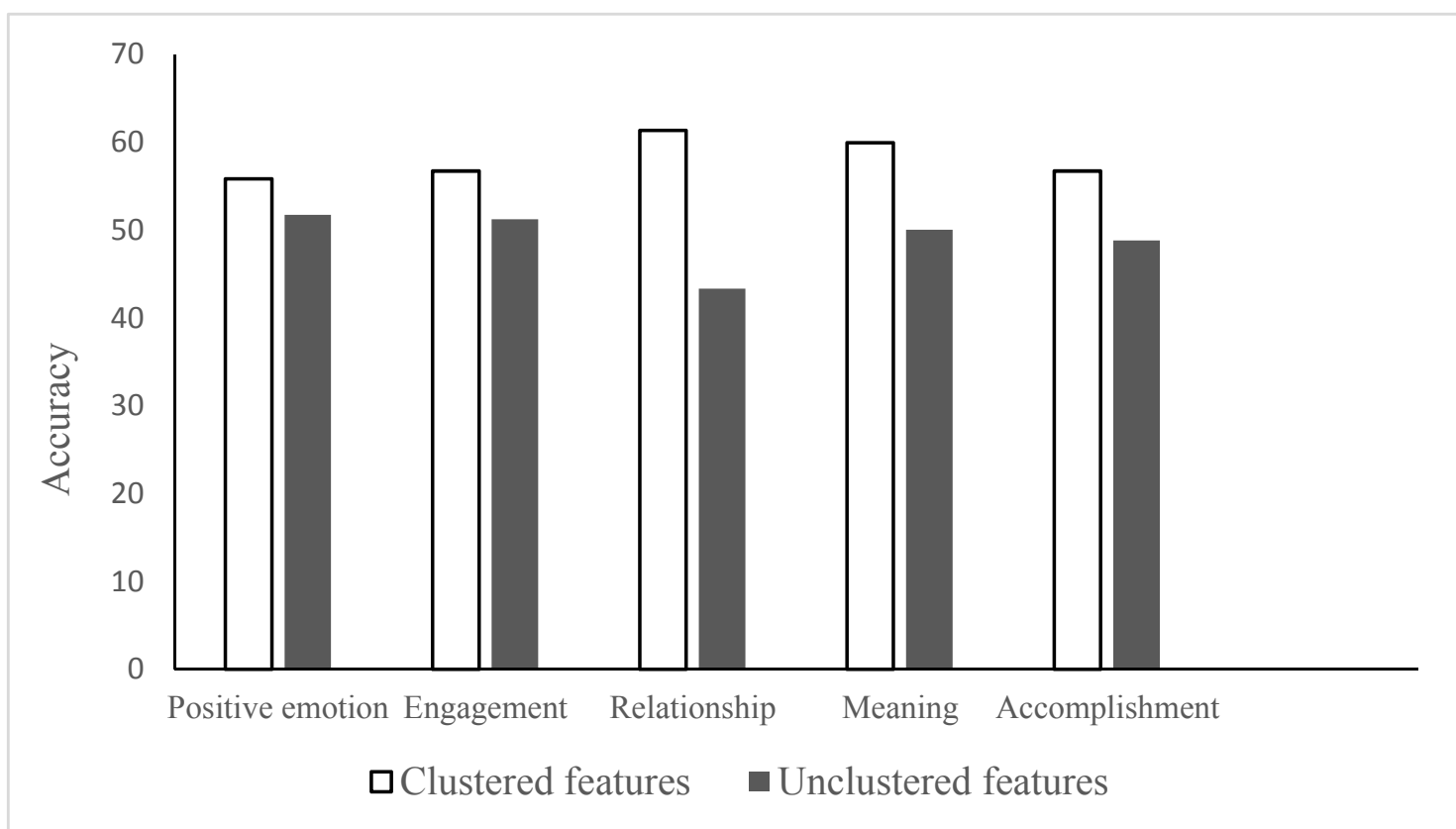

Fig. (4). Binary classification accuracy of the five well-being experience indexes using the clustered $v s$. unclustered physiological and behavioral features.

Table 1. Description statistics of daily well-being measures.

\begin{tabular}{|l|c|c|c|c|c|c|c|}
\hline & Variable & M & SE & 1 & 2 & 3 & 4 \\
\hline 1 & Positive emotion & 4.1831 & 1.06284 & - & - & - & - \\
\hline 2 & Relationship & 4.3285 & 1.02146 & 0.758 & - & - & - \\
\hline 3 & Engagement & 3.8110 & 1.13353 & 0.435 & 0.414 & - & - \\
\hline 4 & Meaning & 3.7297 & 1.07429 & 0.475 & 0.466 & 0.717 & - \\
\hline 5 & Accomplish & 3.7326 & 1.14464 & 0.438 & 0.429 & 0.815 & 0.776 \\
\hline
\end{tabular}

Table 2. Correlation coefficients between the five well-being experience indexes and the physiological and behavioral parameters in the four defined mental states.

\begin{tabular}{|c|c|c|c|c|c|c|}
\hline- & - & $\mathrm{P}$ & $\mathrm{E}$ & $\mathrm{R}$ & $M$ & A \\
\hline \multirow[t]{6}{*}{ Asleep } & HR & -0.139 & -0.058 & $-0.167^{*}$ & $-0.185^{*}$ & -0.130 \\
\hline & HR std & -0.189 & -0.059 & $-0.182^{*}$ & $-0.201^{*}$ & -0.101 \\
\hline & GSR & 0.004 & -0.037 & 0.036 & 0.005 & -0.029 \\
\hline & GSR std & -0.012 & -0.098 & 0.013 & -0.049 & -0.098 \\
\hline & ST & 0.012 & -0.089 & 0.051 & -0.039 & -0.058 \\
\hline & ST std & 0.037 & 0.030 & 0.030 & -0.018 & 0.028 \\
\hline \multirow[t]{6}{*}{ Relaxed } & HR & -0.090 & 0.043 & -0.072 & 0.088 & 0.078 \\
\hline & HR std & -0.182 & 0.037 & $-0.182^{*}$ & -0.171 & -0.038 \\
\hline & GSR & 0.027 & 0.005 & 0.092 & 0.104 & 0.085 \\
\hline & GSR std & 0.026 & -0.041 & 0.088 & 0.056 & 0.041 \\
\hline & ST & -0.017 & -0.042 & 0.017 & 0.047 & 0.011 \\
\hline & ST std & 0.064 & 0.000 & 0.021 & 0.027 & 0.031 \\
\hline \multirow[t]{6}{*}{ High mental load } & HR & -0.001 & $0.178^{* *}$ & 0.050 & $0.295^{* *}$ & $0.216^{*}$ \\
\hline & HR std & -0.122 & -0.047 & -0.081 & -0.091 & -0.059 \\
\hline & GSR & 0.017 & 0.034 & 0.066 & $0.120^{*}$ & $0.116^{*}$ \\
\hline & GSR std & -0.025 & -0.028 & 0.046 & 0.059 & 0.010 \\
\hline & ST & -0.061 & -0.001 & -0.068 & 0.033 & 0.012 \\
\hline & ST std & -0.006 & 0.048 & 0.008 & 0.045 & 0.059 \\
\hline
\end{tabular}




\begin{tabular}{|c|c|c|c|c|c|c|}
\hline \multirow[t]{7}{*}{ High physical load } & HR & -0.080 & 0.014 & -0.082 & 0.091 & 0.032 \\
\hline & HR std & -0.044 & -0.088 & -0.081 & -0.056 & -0.101 \\
\hline & GSR & 0.009 & 0.093 & 0.015 & $0.140^{* * *}$ & 0.104 \\
\hline & GSR std & 0.010 & $0.134^{*}$ & 0.021 & $0.135^{*}$ & $0.108^{*}$ \\
\hline & ST & -0.015 & 0.009 & -0.017 & 0.010 & 0.042 \\
\hline & ST std & 0.038 & $0.136^{*}$ & 0.038 & 0.103 & $0.112^{*}$ \\
\hline & WS & -0.035 & -0.048 & -0.062 & -0.016 & -0.074 \\
\hline
\end{tabular}

Notes: ${ }^{*} p<0.05,{ }^{* *} p<0.01 . \mathrm{std}=$ standard deviation.

$\mathrm{P}=$ positive emotion; $\mathrm{R}=$ relationship; $\mathrm{E}=$ engagement; $\mathrm{A}=$ accomplishment; $\mathrm{M}=$ meaning.

Table 3. Stepwise Regression results for the five well-being experience indexes using physiological and behavioral features.

\begin{tabular}{|c|c|c|}
\hline Variable & Standardized $\beta$ & $\mathrm{t}$ \\
\hline Dependent Variable $=$ Positive emotion & - & - \\
\hline HR std (asleep) & -0.203 & $-3.778^{* * *}$ \\
\hline HR (relaxed) & -0.097 & -1.760 \\
\hline HR (asleep) & -0.149 & $-2.647^{* *}$ \\
\hline HR (high physical load) & -0.120 & $-2.151^{*}$ \\
\hline Overall regression: $\mathrm{F}(4,339)=7.104 * * *$ & - & - \\
\hline Adjusted $\mathrm{R}^{2}=0.066$ & - & - \\
\hline Dependent Variable=Engagement & - & - \\
\hline HR (high mental load) & 0.207 & $3.743^{* * *}$ \\
\hline ST (high physical load) & 0.130 & $2.465^{*}$ \\
\hline HR std (high mental load) & -0.122 & $-2.200^{*}$ \\
\hline Overall regression: $\mathrm{F}(3,340)=7.285^{* * *}$ & - & - \\
\hline Adjusted $\mathrm{R}^{2}=0.052$ & - & - \\
\hline Dependent Variable=Relationship & - & - \\
\hline HR std (aleep) & -0.172 & $-3.297^{* *}$ \\
\hline HR (aleep) & -0.201 & $-3.652^{* * *}$ \\
\hline HR (high physical load) & -0.150 & $-2.744^{* *}$ \\
\hline Overall regression: $\mathrm{F}(3,340)=9.465^{* * *}$ & - & - \\
\hline Adjusted $\mathrm{R}^{2}=0.069$ & - & - \\
\hline Dependent Variable $=$ Meaning & - & - \\
\hline HR (high mental load) & 0.389 & $6.344^{* * *}$ \\
\hline HR std (high mental load) & -0.178 & $-3.276^{* *}$ \\
\hline HR std (relaxed) & -0.136 & $-2.601^{*}$ \\
\hline ST std (high physical load) & 0.121 & $2.397^{*}$ \\
\hline GSR (high physical load) & 0.126 & $2.475^{*}$ \\
\hline HR (high physical load) & -0.136 & $-2.289^{*}$ \\
\hline Overall regression: $\mathrm{F}(6,337)=11.678^{* * *}$ & - & - \\
\hline Adjusted $\mathrm{R}^{2}=0.157$ & - & - \\
\hline dependent Variable=Accomplishment & - & - \\
\hline HR (high mental load) & 0.257 & $4.700^{* * *}$ \\
\hline HR std (high mental load) & -0.146 & $-2.676^{* *}$ \\
\hline ST std (high physical load) & 0.130 & $2.436^{*}$ \\
\hline WS (high physical load) & -0.111 & $-2.075^{*}$ \\
\hline Overall regression: $\mathrm{F}(4,339)=8.070 * * *$ & - & - \\
\hline Adjusted $\mathrm{R}^{2}=0.076$ & - & - \\
\hline
\end{tabular}

Notes: $* p<0.05,{ }^{* *} p<0.01,{ }^{* * *} p<0.001$. std $=$ standard deviation.

\section{DISCUSSION}

In the present study, a daily-life study was conducted to explore the physiological correlates of human well-being experiences based on the PERMA model. The heart rate, galvanic skin response, skin temperature, and walking steps were continuously monitored in 19 participants for 30 days. Bivariate correlation analysis revealed significant correlations between these physiological and behavioral data and the daily well-being experiences in the dimensions of Positive emotion, Engagement, Relationship, Meaning, and Accomplishment. 
Stepwise regression analyses showed that all five well-being experience indexes could be significantly predicted by the physiological and behavioral parameters. A further binary classification analysis reported recognition accuracies between $55.8 \%$ and $61.3 \%$ for these five PERMA well-being indexes. These results provide evidence for the physiological basis of the PERMA-based well-being.

To fully extract useful information from the continuous recordings of the daily activities, four mental states were defined before all these analyses, using an individualized clustering method. The k-means clustering approach could, in general, be applicable in many other psychological research scenarios, especially in the context of the increasing popularity of wearable sensing technology. The wearable sensing technology has enabled us to record a huge amount of human activity data without interrupting the participant and provided a more detailed description of human behaviors. However, the amount of data has posed critical challenges to researchers: labeling the corresponding daily life events of these data in a retrospective way might be very time-consuming and subject to recall bias; labeling these data in a real-time manner (e.g. by using the experience sampling method) could severely interrupt the participant's daily activities, therefore, is not feasible in many situations (e.g. attending meetings). The proposed approach in the present study provides a feasible solution to this issue: the large amount of unlabeled physiological data was translated into interpretable psychological states that could be better utilized for further analysis.

The clustered physiological and behavioral data significantly predicted the five daily well-being indices, while the unclustered data failed to turn in any significant results. The binary classification results further illustrate the effectiveness of the clustering method: using the unclustered features, the accuracies did not outperform the chance level. There could be better categorization strategies (e.g. more categories of daily life events) that could further improve the results. Nevertheless, the study suggested that the categorization procedure could effectively extract important contextual information from the daily recordings to facilitate data interpretation.

Although not all of the five PERMA well-being experiences have been systematically investigated, and most of the previous studies have been conducted in laboratory environments, the bivariate correlation analysis results are in line with previous findings. The daily experience of Relationship was negatively correlated with the HR and its standard deviation during asleep state, as well as the HR standard deviation during a relaxed state. Although nonsignificant, the correlations between Positive emotion and the physiological measurements showed a negative association between the HR during high physical load state and the HR and its standard deviation during asleep state. These findings are in line with previous researches, suggesting that positive emotions have the effect of reducing cardiovascular arousal, leading to reduced heart rate and heart rate variability (HRV, similar to the HR standard deviation in our study) during a high positive emotion state $[6,30]$. Several studies have documented the "undoing effect", which points out positive emotions like amusement and contentment can quell any existing cardiovascular reactivity caused by negative emotions [58]. As the cardiovascular reactivity sparked by certain negative emotions prepares the body for specific actions, the positive emotions speed recovery from this cardiovascular reactivity and return the body to mid-range levels of activation more suitable for pursuing a range of behavioral options [28]. Meanwhile, there are also evidences suggesting that happiness associated with social bonding is characterized by increased activation of vaso-vagal branch of the parasympathetic nervous system [29, 30], predicting reduced heart rate and heart rate variability. While previous studies have focused on the after effect of positive emotions, these findings suggest that daily physiological activities can influence the post hoc evaluation of Positive emotion.

Similar positive correlations between HR during high mental load state were observed for the well-being experiences of Engagement, Meaning, and Accomplishment. This piece of the result is consistent with previous studies on flow experiences: the experience of flow has been characterized by a relatively sympathetic enhancement, leading to increased heart rate $[59,60]$. The concept of flow shares a lot in common with these three well-being experiences, since flow is normally described as a mental state in which a person is fully engaged in an activity towards a meaningful output and selfaccomplishment [61 - 63]. These findings are also in line with recent studies on motivational engagement, reward anticipation, as well as reward pursuit, all of which suggest a positive correlation between cardiovascular arousal and the above concepts [26, 30, 31]. Apart from the HR in the high mental load state, Engagement, Meaning, and Accomplishment were also significantly linked with other physiological measures, such as skin temperature, galvanic skin response, and walking steps. Although studies on these physiological correlates are limited, the results revealed multi-dimensional activity patterns for these well-being experiences beyond positive emotions.

The stepwise regression analyses further suggested that all these five daily well-being experience indexes can be significantly predicted by using a combination of physiological and behavioral parameters. The primary contributors are the HRs in different mental states, suggesting a critical role of cardiovascular functions in well-being experiences [64]. Furthermore, $55.8 \% \sim 61.3 \%$ binary classification accuracies were obtained for recognizing a high or low self-report of these daily well-being experiences. Establishing such a type of link has been investigated in many other fields using mobile sensing technology, for example, using mobile phone data for personality recognition [45], mood analyzing [65], or stress investigation in family and working place [39]. The results show that daily well-being experiences can be predicted using the whole-day physiological and behavioral measurement, suggesting a close link between the psychological states and the physiological data.

\section{CONCLUSION}

This study has several limitations that should be noted. First, the sample size is small, limiting the application of a possibly more standard multi-level analysis procedure. While 
we made the efforts to do within-participant normalization to alleviate the problem, further studies with a larger sample size are required, and substantially more efforts are necessary to organize the study for long-term participation. Secondly, the categorization of the four states by using heart rate and walking steps data is only an oversimplified definition of the daily activities. Extracting richer contextual information is expected to provide a more effective estimation of the psychological states, such as well-being, with advanced sensing techniques, such as a more precise classification of the physical activities, more dimensions of physiological data, etc. Thirdly, although significant, the variances explained for each PERMA dimensions in the regression analysis are still relatively low. Advanced data analysis methods, together with a larger sample, might help improve the effectiveness of the models.

\section{ETHICS APPROVAL AND CONSENT TO PARTI- CIPATE}

This study was approved by the Research Ethics Committee of Tsinghua University, China under approval no. 2016-04.

\section{HUMAN AND ANIMAL RIGHTS}

No animals were used in this research. All human research procedures followed were in accordance with the ethical standards of the institutional committee and with the Declaration of Helsinki.

\section{CONSENT FOR PUBLICATION}

Participants were informed about the aims of the study and gave informed consent before data collection.

\section{AVAILABILITY OF DATA AND MATERIALS}

The data supporting the findings of the article is available from corresponding author [D.Z] upon reasonable request.

\section{FUNDING}

This work was supported by the National Natural Science Foundation of China (61977041), the National Social Science Foundation of China (17ZDA323), the MOE (Ministry of Education China) Project of Humanities and Social Sciences (17YJA190017), and Tsinghua University School of Social Sciences \& Institute for Data Science.

\section{CONFLICT OF INTEREST}

The authors declare that they have no conflicts of interest concerning their authorship or the publication of this article.

\section{ACKNOWLEDGEMENTS}

Declared none.

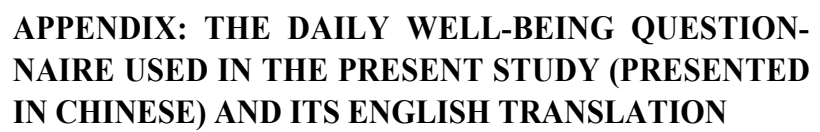

APPENDIX: THE DAILY WELL-BEING QUESTIONIN CHINESE) AND ITS ENGLISH TRANSLATION
请你对下面 1-6 题中的陈述按照其符合你实际情况的程度在 6 个等级上进行评分, 并选择一个合适的数值。

这 6 个等级代表了你对于该陈述同意的程度, 1 代表非常不同意,

2 代表不同意, 3 代表略微不同意, 4 代表略微同意,

5 代表同意, 6 代表非常同意。第 7 题为开放性问题,

请输入文字答案。

Below $1-6^{\text {th }}$ items are the statements with which you may agree or disagree. Using the 1-6 scale below, indicate your agreement with each item by choosing the appropriate number. The 6-point scale is: 1=strongly disagree, 2=disagree, $3=$ slightly disagree, $4=$ slightly agree, $5=$ agree, $6=$ strongly agree. The $7^{\text {th }}$ item is an open question with which you can enter the answer by words.

1. 跟这一周的其他几天相比, 我对今天的生活感到满意。

I am satisfied with life today compared to other days of this week.

2. 我感到今天过的很快乐。

I feel happy today.

3. 我对今天与其他人的相处感到满意。

I am satisfied with the relationship with others today.

4. 我对今天所从事的活动都非常投入。

I was engaged and absorbed in activities today.

5. 今天对我来说是很有成就感的一天。

I gained a great sense of accomplishment today.

6. 我感到今天过的很有意义。

I felt very meaningful today.

\section{7. 今天对你而言有什么印象深刻的事件发生?}

What were the most impressive events for you today?

\section{REFERENCES}

[1] Khaw D, Kern M. A cross-cultural compariso.n of the PERMA model of well-being.Undergraduate Journal opf Psychology at Berkeley. University of California 2014; 8.

[2] Perissinotto CM, Stijacic Cenzer I, Covinsky KE. Loneliness in older persons: a predictor of functional decline and death. Arch Intern Med 2012; 172(14): 1078-83.

[http://dx.doi.org/10.1001/archinternmed.2012.1993] [PMID: 22710744]

[3] Cohen S, Pressman SD. Positive affect and health. Curr Dir Psychol Sci 2006; 15(3): 122-5.

[http://dx.doi.org/10.1111/j.0963-7214.2006.00420.x]

[4] Hawkley LC, Cacioppo JT. Loneliness matters: A theoretical and empirical review of consequences and mechanisms. Ann Behav Med 2010; 40(2): 218-27.

[http://dx.doi.org/10.1007/s12160-010-9210-8] [PMID: 20652462]

[5] Lindfors P. Physiological correlates of mental well-being mental wellbeing. Springer 2013; pp. 259-74.

[6] Pressman SD, Cohen S. Does positive affect influence health? Psychol Bull 2005; 131(6): 925-71.

[http://dx.doi.org/10.1037/0033-2909.131.6.925] [PMID: 16351329]

[7] Steptoe A, Dockray S, Wardle J. Positive affect and psychobiological processes relevant to health. J Pers 2009; 77(6): 1747-76. [http://dx.doi.org/10.1111/j.1467-6494.2009.00599.x] [PMID: 19796062]

[8] Steptoe A, Wardle J. Positive affect and biological function in everyday life. Neurobiol Aging 2005; 26(1)(Suppl. 1): 108-12. 
[http://dx.doi.org/10.1016/j.neurobiolaging.2005.08.016] [PMID: 16213629]

[9] Stevenson B, Wolfers J. Economic growth and subjective well-being: Reassessing the Easterlin paradox (No w14282). National Bureau of Economic Research 2008

[http://dx.doi.org/10.3386/w14282]

[10] Keyes CL. The mental health continuum: From languishing to flourishing in life. J Health Soc Behav 2002; 43(2): 207-22. [http://dx.doi.org/10.2307/3090197] [PMID: 12096700]

[11] Huppert FA, So T. What percentage of people in Europe are flourishing and what characterises them? meeting of the OECD/ISQOLS meeting. July 23/24 2009; Florence. 2009.

[12] Fredrickson BL, Losada MF. Positive affect and the complex dynamics of human flourishing. Am Psychol 2005; 60(7): 678-86. [http://dx.doi.org/10.1037/0003-066X.60.7.678] [PMID: 16221001]

[13] Diener E, Wirtz D, Tov W, et al. New well-being measures: Short scales to assess flourishing and positive and negative feelings. Soc Indic Res 2010; 97(2): 143-56

[http://dx.doi.org/10.1007/s11205-009-9493-y]

[14] Seligman ME. Flourish: A visionary new understanding of happiness and well-being. Simon and Schuster 2012.

[15] Hone LC, Jarden A, Schofield GM, Duncan S. Measuring flourishing: The impact of operational definitions on the prevalence of high levels of well-being. Int J Wellbeing 2014; 4(1): 62-90. [http://dx.doi.org/10.5502/ijw.v4i1.4]

[16] Ryff CD, Keyes CLM. The structure of psychological well-being revisited. J Pers Soc Psychol 1995; 69(4): 719-27. [http://dx.doi.org/10.1037/0022-3514.69.4.719] [PMID: 7473027]

[17] Huppert FA, So TT. Flourishing across Europe: Application of a new conceptual framework for defining well-being. Soc Indic Res 2013; 110(3): 837-61.

[http://dx.doi.org/10.1007/s11205-011-9966-7] [PMID: 23329863]

[18] Deci EL, Ryan RM. The" what" and" why" of goal pursuits: Human needs and the self-determination of behavior. Psychol Inq 2000; 11(4): 227-68.

[http://dx.doi.org/10.1207/S15327965PLI1104_01]

[19] Seligman ME. Authentic happiness: Using the new positive psychology to realize your potential for lasting fulfillment. Simon and Schuster 2004.

[20] Waterman AS, Schwartz SJ, Conti R. The implications of two conceptions of happiness (hedonic enjoyment and eudaimonia) for the understanding of intrinsic motivation. J Happiness Stud 2008; 9(1): 41-79.

[http://dx.doi.org/10.1007/s10902-006-9020-7]

[21] Donlin AA. Vocational identity and well-being among diverse, upperdivision health science undergraduates in the United States (247) Ann Arbor: California State University. Long Beach: Reprinted 2014

[22] Baltzell A, Akhtar VL, McCarthy J, Hurley D, Martin I. Happiness and well-being models: Empirical support from high school coaching study. Athl Insight 2014; 6(2): 125-35.

[23] Butler J, Kern ML. The PERMA-Profiler: A brief multi-dimensional measure of flourishing. Int J Wellbeing 2016; 6(3): 1-48.

[http://dx.doi.org/10.5502/ijw.v6i3.526]

[24] Cacioppo JT, Berntson GG, Larsen JT, Poehlmann KM, Ito TA. Handbook of emotions 2000; 2: pp. The psychophysiology of emotion. 173-91.

[25] Levenson RW, Ekman P, Heider K, Friesen WV. Emotion and autonomic nervous system activity in the Minangkabau of west Sumatra. J Pers Soc Psychol 1992; 62(6): 972-88. [http://dx.doi.org/10.1037/0022-3514.62.6.972] [PMID: 1619551]

[26] Kreibig SD, Gendolla GH, Scherer KR. Psychophysiological effects of emotional responding to goal attainment. Biol Psychol 2010; 84(3): 474-87.

[http://dx.doi.org/10.1016/j.biopsycho.2009.11.004] [PMID: 19941932]

[27] Neumann SA, Waldstein SR. Similar patterns of cardiovascular response during emotional activation as a function of affective valence and arousal and gender. J Psychosom Res 2001; 50(5): 245-53. [http://dx.doi.org/10.1016/S0022-3999(01)00198-2]

[PMID: 11399281]

[28] Fredrickson BL, Levenson RW. Positive emotions speed recovery from the cardiovascular sequelae of negative emotions. Cogn Emotion 1998; 12(2): 191-220.

[http://dx.doi.org/10.1080/026999398379718] [PMID: 21852890]

[29] Porges S W. Emotion: An evolutionary by-product of the neural regulation of the autonomic nervous system The integrative neurobiology of affiliation 1997; 807: 62-7.
[30] Shiota MN, Neufeld SL, Yeung WH, Moser SE, Perea EF. Feeling good: autonomic nervous system responding in five positive emotions. Emotion 2011; 11(6): 1368-78.

[http://dx.doi.org/10.1037/a0024278] [PMID: 22142210]

[31] Fowles DC, Fisher AE, Tranel DT. The heart beats to reward: The effect of monetary incentive on heart rate. Psychophysiology 1982; 19(5): 506-13.

[http://dx.doi.org/10.1111/j.1469-8986.1982.tb02577.x] [PMID: 7134355]

[32] Sonkusare S, Breakspear M, Guo C. Naturalistic Stimuli in Neuroscience: Critically Acclaimed. Trends Cogn Sci (Regul Ed) 2019; 23(8): 699-714.

[http://dx.doi.org/10.1016/j.tics.2019.05.004] [PMID: 31257145]

[33] Hu X, Chen J, Wang F, Zhang D. Ten challenges for EEG-based affective computing. Brain Science Advances 2019; 5(1): 1-20. [http://dx.doi.org/10.1177/2096595819896200]

[34] Zhang Y, Qin F, Liu B, Qi X, Zhao Y, Zhang D. Wearable Neurophysiological Recordings in Middle-School Classroom Correlate With Students' Academic Performance. Front Hum Neurosci 2018; 12: 457.

[http://dx.doi.org/10.3389/fnhum.2018.00457] [PMID: 30483086]

[35] Lane N D, Choudhury T, Zhao F. 2011; Mobile sensing: challenges, opportunities and future directions. Ubiquitous Computing 637-8. [http://dx.doi.org/10.1145/2030112.2030253]

[36] Kravets and Lane. What is next for mobile sensing?. GetMobile 2016.

[37] Siddharth P, Patel AN, Jung TP, Sejnowski TJ. A Wearable MultiModal Bio-Sensing System Towards Real-World Applications. IEEE Trans Biomed Eng 2019; 66(4): 1137-47.

[http://dx.doi.org/10.1109/TBME.2018.2868759] [PMID: 30188809]

[38] Hofmann W, Wisneski DC, Brandt MJ, Skitka LJ. Morality in everyday life. Science 2014; 345(6202): 1340-3.

[http://dx.doi.org/10.1126/science.1251560] [PMID: 25214626]

[39] Ryan RM, Bernstein JH, Brown KW. Weekends, Work, and WellBeing: Psychological Need Satisfactions and Day of the Week Effects on Mood, Vitality, and Physical Symptoms. J Soc Clin Psychol 2010; 29(1): 95-122.

[http://dx.doi.org/10.1521/jscp.2010.29.1.95]

[40] Bryson A, MacKerron G. Are you happy while you work? Econ J (Lond) 2017; 127(599): 106-25.

[http://dx.doi.org/10.1111/ecoj.12269]

[41] Kashdan TB, Steger MF. Curiosity and pathways to well-being and meaning in life: Traits, states, and everyday behaviors. Motiv Emot 2007; 31(3): 159-73.

[http://dx.doi.org/10.1007/s11031-007-9068-7]

[42] Killingsworth MA, Gilbert DT. A wandering mind is an unhappy mind. Science 2010; 330(6006): 932-2.

[http://dx.doi.org/10.1126/science.1192439] [PMID: 21071660]

[43] Robinson MD. The Reactive and Prospective Functions of Mood: Its Role in Linking Daily Experiences and Cognitive Well-being. Cogn Emotion 2000; 14(2): 145-76. [http://dx.doi.org/10.1080/026999300378914]

[44] Picard RW, Vyzas E, Healey J. Toward machine emotional intelligence: Analysis of affective physiological state. IEEE Trans Pattern Anal Mach Intell 2001; 23(10): 1175-91.

[http://dx.doi.org/10.1109/34.954607]

[45] Kim S, Nakamura H, Yoshida T, et al. Development of a wearable system module for monitoring physical and mental workload. Telemed J E Health 2008; 14(9): 939-45.

[http://dx.doi.org/10.1089/tmj.2008.0019] [PMID: 19035804]

[46] Poh MZ, Swenson NC, Picard RW. A wearable sensor for unobtrusive, long-term assessment of electrodermal activity. IEEE Trans Biomed Eng 2010; 57(5): 1243-52.

[http://dx.doi.org/10.1109/TBME.2009.2038487] [PMID: 20172811]

[47] Paradiso R, Faetti T, Werner S. Wearable monitoring systems for psychological and physiological state assessment in a naturalistic environment. 2011 Annual International Conference of the IEEE Engineering in Medicine and Biology Society.

[http://dx.doi.org/10.1109/IEMBS.2011.6090427]

[48] Csikszentmihalyi M, Mehl MR, Conner TS. Handbook of research methods for studying daily life. Guilford Publications 2013.

[49] Cacioppo JT, Tassinary LG. Inferring psychological significance from physiological signals. Am Psychol 1990; 45(1): 16-28. [http://dx.doi.org/10.1037/0003-066X.45.1.16] [PMID: 2297166]

[50] Trull TJ, Ebner-Priemer U. The Role of Ambulatory Assessment in Psychological Science. Curr Dir Psychol Sci 2014; 23(6): 466-70. [http://dx.doi.org/10.1177/0963721414550706] [PMID: 25530686]

[51] Reid SC, Kauer SD, Dudgeon P, Sanci LA, Shrier LA, Patton GC. A 
mobile phone program to track young people's experiences of mood, stress and coping. Development and testing of the mobiletype program. Soc Psychiatry Psychiatr Epidemiol 2009; 44(6): 501-7. [http://dx.doi.org/10.1007/s00127-008-0455-5] [PMID: 19011723]

[52] Lathia N, Pejovic V, Rachuri KK, Mascolo C, Musolesi M, Rentfrow PJ. Smartphones for large-scale behavior change interventions. IEEE Pervasive Comput 2013; 12(3): 66-73.

[http://dx.doi.org/10.1109/MPRV.2013.56]

[53] Patel S, Ruoff L, Ahmed T, Unadkat T, Lee J. Validation of Basis Science Advanced Sleep Analysis.

[54] Boletsis C, Mccallum S, Landmark BF. The Use of Smartwatches for Health Monitoring in Home-Based Dementia Careinternational conference on human aspects of it for aged population. Los Angeles, CA, USA 2015.

[55] Myrtek M, Ed. Heart and emotion: Ambulatory monitoring studies in everyday life. Seattle, WA: Hogrefe \& Huber 2004

[56] Payne RL, Rick JT. Heart rate as an indicator of stress in surgeons and anaesthetists. J Psychosom Res 1986; 30(4): 411-20. [http://dx.doi.org/10.1016/0022-3999(86)90080-2] [PMID: 3761226]

[57] Ira GH Jr, Whalen RE, Bogdonoff MD. Heart rate changes in physicians during daily "stressful" tasks. J Psychosom Res 1963; 7(2): $147-50$.

[http://dx.doi.org/10.1016/0022-3999(63)90025-4] [PMID: 14071861]

[58] Fredrickson BL, Mancuso RA, Branigan C, Tugade MM. The undoing effect of positive emotions. Motiv Emot 2000; 24(4): 237-58.
[http://dx.doi.org/10.1023/A:1010796329158] [PMID: 21731120]

[59] Rodríguez-Sánchez AM, Schaufeli W, Salanova M, Cifre E, Sonnenschein M. Enjoyment and absorption: An electronic diary study on daily flow patterns. Work Stress 2011; 25(1): 75-92.

[http://dx.doi.org/10.1080/02678373.2011.565619]

[60] Gaggioli A, Cipresso P, Serino S, Riva G. Psychophysiological correlates of flow during daily activities. Stud Health Technol Inform 2013; 191: 65-9.

[PMID: 23792845]

[61] Chen H. Flow on the net-detecting Web users' positive affects and their flow states. Comput Human Behav 2006; 22(2): 221-33.

[http://dx.doi.org/10.1016/j.chb.2004.07.001]

[62] Csikszentmihalyi M. Beyond boredom and anxiety, second printing. San Francisco: Jossey-Bass 1977.

[63] Ghani JA, Deshpande SP. Task characteristics and the experience of optimal flow in human-computer interaction. J Psychol 1994; 128(4): 381-91.

[http://dx.doi.org/10.1080/00223980.1994.9712742]

[64] Kohlisch O, Schaefer F. Physiological changes during computer tasks: responses to mental load or to motor demands? Ergonomics 1996; 39(2): 213-24.

[http://dx.doi.org/10.1080/00140139608964452] [PMID: 8851526]

[65] Moodscope: building a mood sensor from smartphone usage patterns. Proceeding of the 11th annual international conference on Mobile systems, applications, and services.

\section{(C) 2020 Feng et al.}

This is an open access article distributed under the terms of the Creative Commons Attribution 4.0 International Public License (CC-BY 4.0), a copy of which is available at: https://creativecommons.org/licenses/by/4.0/legalcode. This license permits unrestricted use, distribution, and reproduction in any medium, provided the original author and source are credited. 